\title{
PREPARAÇÃO E COOPERAÇÃO INTERNACIONAL EM CENÁRIOS DE EMERGÊNCIA SANITÁRIA: FRAGILIDADES ANUNCIADAS NUM CONTEXTO DE ECONOMIA GLOBAL
}

\author{
INTERNATIONAL PREPAREDNESS AND COOPERATION IN HEALTH EMERGENCY \\ SCENARIOS: FRAGILITIES ANNOUNCED IN A GLOBAL ECONOMY CONTEXT
}

\author{
Paulo Nuno Nossa \\ Departamento de Geografia e Turismo \\ CEGOT; Universidade de Coimbra; Portugal \\ paulonnossa@gmail.com
}

\begin{abstract}
RESUMO
No presente texto, o autor apresenta um conjunto de dados históricos que documentam a progressiva unificação microbiana do mundo à medida que a agricultura, o comercio e a tecnologia de transporte nos tornaram mais próximos. Nas últimas décadas, fundamentalmente através da intensificação do processo de globalização e de hiperconetividade de pessoas e bens, a frequência de surtos pandémicos tem crescido significativamente, obrigando à revisão do Regulamento Sanitário Internacional (2005) e à adoção de compromisso internacionais de preparação em saúde global, cujos níveis de alerta ainda são escassas em diversas partes do globo. Partindo das lições aprendidas com as mais recentes epidemias de ébola, discutem-se as fragilidades encontradas ao nível local e regional, bem como o modelo de atuação de atores internacionais relevantes. A eclosão da atual pandemia gerada pelo SARS-CoV2, pela rapidez de propagação e pela sua extensão, obriga-nos a refletir para além dos dados epidemiológicos básicos, propondo-se uma leitura geográfica, analisando o contexto de interdependência gerado globalização dos transportes e pela segmentação das cadeias de produção abruptamente interrompidas com a emergência da epidemia. As consequências futuras a retirar deste cenário disruptivo ainda são incertas, mas algumas evidencias sugerem que este tipo de acontecimentos poderá ter algum potencial para acelerar processo de mudança no contexto da globalização das trocas.
\end{abstract}

Palavras-chave: Epidemias. Globalização. SARS-CoV2. Preparação. Transportes.

\begin{abstract}
In the present text, the author presents a set of historical data that document a progressive microbial unification of the world as agriculture, trade and transport technology brought us closer. In the last decades, fundamentally through the intensification of the globalization process and hyperconnectivity of people and goods, the frequency of pandemic outbreaks has grown significantly, forcing the revision of the International Health Regulations (2005) and the adoption of international commitments to prepare for global health, whose alert levels are still scarce in different parts of the globe. Based on the lessons learned from the most recent Ebola epidemics, the weaknesses found at the local and regional level are discussed, as well as the role model of relevant international actors. The outbreak of the current pandemic generated by SARS-CoV2, due to the speed of propagation and its geographical extension, obliges us to reflect beyond the basic epidemiological data, proposing a geographical reading, analyzing the context of interdependence generated by the globalization of transport and the segmentation of production chains abruptly interrupted with the emergence of the epidemic. The future consequences to be drawn from this disruptive scenario are still uncertain, but some evidence suggests that this type of outbreak may have some potential to accelerate the process of change in the context of the globalization of trades.
\end{abstract}

Keywords: Epidemics. Globalization. SARS-CoV2. Preparedness. Transport.

Recebido em: 10/05/2020

Aceito para publicação em: 26/05/2020. 
"Se é comum dizer-se "o que é passado é prólogo", então existe uma ameaça muito real de uma pandemia altamente letal que se move rapidamente de um patógeno respiratório matando 50 a 80 milhões de pessoas e destruindo quase $5 \%$ da economia mundial. Uma pandemia global nessa escala seria catastrófica, criando um caos generalizado, instabilidade e insegurança. O mundo não está preparado».

GPMB/WHO - Annual Report (Set. 2019:6)

\section{INTRODUÇÃO}

De uma forma consistente, desde a década de 90 do século passado a literatura científica produziu sistematicamente um conjunto de alertas relacionados com o risco de (re)emergência de doenças infeciosas e o potencial de impacto de ameaça para a espécie humana que lhes está associado (Farmer, 1996; Fidler, 1996). À medida que o processo de globalização progrediu, "abraçando e encolhendo o mundo", agravou um conjunto de "cargas simbólicas complexas" que, na visão de Farmer (1996), desde sempre estigmatizaram na origem, povos, nações e comportamentos, comprometendo a eficácia e clarividência de muitas atuações. Estes alertas, recorrentes, que diligenciavam um comprometimento político dos Estados, eram fundamentados não só pela sofisticação do conhecimento biomédico, mas também pelo olhar atento da história e da antropologia médica que colhia no passado importantes lições supostamente aprendidas.

Desde sempre, a humanidade enfrentou com maior ou menor severidade as consequências das patologias infeciosas sendo que, ao longo da história, os grandes surtos epidémicos originaram e transformaram significativamente as sociedades e, em alguns casos, as mudanças políticas e tecnológicas foram, elas próprias os motores da eclosão de surtos violentos. A domesticação de animais no neolítico concorreu para o aparecimento de um conjunto de "novas" doenças causadas por germes, transmitidos horizontalmente, como foi o caso da tuberculose e das febres eruptivas agudas provocadas pelos pox vírus ${ }^{2}$. A bactéria da tuberculose humana (Mycobacterium tuberculosis) exibe elevada semelhança com a Mycobacterium bovis, pelo que a difusão desta zoonose foi ampliada pelo movimento dos rebanhos e transação de animais, incluindo a sua introdução noutros continentes, podendo ter-se instalado em populações humanas europeias através da ingestão de leite contaminado (Ujvari, 2008:31).

Admite-se que a primeira epidemia grave de uma doença coletiva foi registada por Tucídides em Ática (430 a.C.), pelo que também ficou conhecida como «peste de Atenas»: «não havia memória de nada comparável, nem enquanto pestilência, nem enquanto destruição de vidas humanas (...) era a primeira vez que tratavam o mal e estavam em face do desconhecido» (Grmek, 1996:167). A dominação política e extensão geográfica do Império Romano gerou a primeira unificação microbiana da história. Até à formação do Império, na Europa, não havia registo de lepra que só na era helenística iniciou a sua expansão no Oriente mediterrânico. A mobilidade dos exércitos, dos escravos e a deslocação forçada e/ou voluntária de populações na área dominada pelo Império Romano foi acompanhada pela emergência de sucessivos e mortíferos surtos de doenças infeciosas, mais ou menos contidas no espaço que, pela sua frequência e letalidade foram objeto de menção por parte de historiadores como Plutarco (século II): «Ou bem que estas doenças novas surgem realmente pela primeira vez e houve, portanto, mudanças na própria natureza, ou bem que todas as doenças existem desde sempre mas a sua aparição escapou à atenção dos médicos.» (Protos de table, VIII, 9; apud Grmek, 1996:169). A peste, provocada pelo bacilo Yersinia pestis, emerge na Europa no século VI, provavelmente originária do Egito, enfraquece severamente o Império Bizantino e matem manifestações mortíferas no século XIV, talvez a mais mortífera de todos os tempos, com possíveis repercussões na aceleração do fim do feudalismo (Nossa, 2001). Com a abertura do mundo, através de fluxos intercontinentais e encurtamento da distância tempo pela rota das caravelas quinhentistas, transportando entre portos portadores sintomáticos ou assintomáticos de doenças infeciosas, bem como reservatórios animais, ocorreu uma nova e significativa alteração do padrão sanitário mundial (Nossa, 2001). A par das trocas comerciais, da introdução de plantas e animais entre continentes, o contacto com a Europa revelou-se de risco do ponto de vista sanitário. Para Meade (1988) deve-se aos descobrimentos, sobretudo do

\footnotetext{
${ }^{2}$ Poxviridae [pox - vesiculas] é uma família de vírus que têm como principal característica a capacidade de infetar tanto os animais vertebrados como também os invertebrados, como é o caso do vírus vaccinia, o qual foi usado com sucesso como vacina para erradicar o vírus da varíola (Buller \&Palumbo, 1991).

DOI:http://dx.doi.org/10.14393/Hygeia0054631 Hygeia Edição Especial: Covid-19, Jun./2020 p.321 - 335, pág.322
} 
continente Americano, a introdução de doenças como a malária, lepra, tifo, varíola, cólera e peste bubónica. Para além da forte dominação política e cultural a que foram sujeitos muitos dos povos autóctones, estas novas patologias revelaram-se fatais, conduzindo em menos de um século à extinção de inúmeras populações locais, como os ameríndios que receberam Colombo em St. Domingo (Meade, 1988), admitindo-se também que a varíola terá sido um forte aliado de Hernan Cortés na derrota do Império Asteca (1520). Tal como refere Pamuk (2020), a partir da década de 1850, viajar de barco a vapor foi cada vez mais acessível, em termos de custo, conforto e distância tempo, transformando os peregrinos que viajavam para as cidades muçulmanas de Meca e Medina nos mais prolíficos portadores e disseminadores de patologias infeciosas, estigma que carregaram durante décadas, levando os britânicos a montarem em Alexandria um gabinete líder mundial em quarentena.

A história demonstra que, sempre que o processo de internacionalização e de globalização intensificou o seu passo, a (re)emergências de doenças infeciosas acompanhou o processo de interdependência impondo os seus tributos, alargando progressivamente a sua escala de atuação e nível de letalidade, levando à inutilidade da clássica distinção entre assuntos internos e externos, exigindo de uma forma inadiável a adoção de estratégias globais, coordenadas e sincronizadas.

Depois do aparente controlo da morbilidade causada por doenças infeciosas nas sociedades ocidentais, com recurso à vacinação, educação, urbanismo e antibioterapia, induzindo um forte declínio de mortalidade prematura por infeções entéricas, infeções respiratórias, tuberculose e infeções maternas nos países de rendimento médio e elevado, decretando o predomínio das patologias crónicodegenerativas, desvalorizámos a evidencia de que no mundo, fundamentalmente no denominado "Sul global", prevalecem bolsas endémicas de malária, cólera, ébola entre outras, que a intensificação das trocas e o aperfeiçoamento dos meios de transporte e vias de comunicação habilita a fazer viagens de longo curso, intercontinentais, algumas vezes sem escala, potenciadas pelo fluxo crescente de turistas e viajantes, bem como pelo comércio de bens alimentares e matérias primas, movendo vírus e bactérias.

Como discutiremos adiante, não são apenas os processos políticos e comerciais assentes numa interdependência das cadeias de valor do crescente fluxo de comércio internacional que, isoladamente, ameaçam de forma significativa a estabilidade sanitária à escala global. Desde meados da década de 1990 que eclosões regulares de surtos epidémicos, potenciados pela debilidade local ou regional de populações empobrecidas, Estados vulneráveis, com fracos níveis de vigilância sanitária e com sistemas de saúde frágeis, têm fornecido evidencia significativa para que organizações internacionais e Estados reforcem níveis de alerta e cooperação na defesa da saúde global. Num curto espaço de tempo, entre 2011 e 2018, a OMS registou 1483 epidemias em 172 países demonstrando o seu potencial de letalidade e de disrupção económica e social que urge prevenir (GPMB, 2019).

\section{TRÊS DÉCADAS DE ALERTAS CRESCENTES E INCOMPREENDIDOS}

Wang et al. (2020), num artigo publicado em plena pandemia causada pelo novo corona vírus (2019$\mathrm{nCoV}$ ), reflete sobre o potencial de aprendizagem que não tem sido totalmente aproveitado quando da eclosão de vírus zoonóticos emergentes (EZV) nos últimos 30 anos (Tab.1), geradores de graves ameaças à saúde humana, debatendo a importância de alcançarmos informação cientificamente fundamentada, equilibrada e multidisciplinar, compreendendo onde, como, porquê, e que riscos estão associados à venda e consumo de animais selvagens em mercados regionais mas de alcance global, através de práticas de importação ou intensificação de viajantes.

Num passado muito recente, excetuando a atual pandemia gerada por SARS-CoV2, quer pela frequência quer pela emergência de saúde pública que geraram, os surtos causados pelo ebolavirus estão entre os mais bem documentados, nomeadamente os surtos de 2014-16 e 2018-19, com a publicação de diversos artigos de revisão onde se discutem as perspetivas geográfico-sanitárias reproduzidas na literatura bem como as lições aprendidas.

Ao contrário do que ocorreu com os emergentes surtos de SARS (2002) e com a MERS (2012), o padrão epidemiológico do Ébola (Ebola virus desease - EVD), congrega uma mistura de contextos que, progressivamente se vão complexificando, desde a aparição inicial em 1976. No presente, associamse questões estruturais clássicas sobre desenvolvimento, com questões de mobilidade populacional por causa económica, deslocações forçadas de populações por conflito militar, com alguns traços de modernidade marcados pelo aumento da conectividade entre territórios, quer a nível regional quer a nível internacional. 
Tabela 1- Resumo das características dos principais surtos de vírus zoonóticos emergentes

\begin{tabular}{|c|c|c|c|c|}
\hline & $\begin{array}{l}\text { Ano do primeiro } \\
\text { surto/epidemia(s) }\end{array}$ & $\begin{array}{l}\text { Países } \\
\text { origem } \\
\text { /regiões } \\
\text { afetadas }\end{array}$ & $\begin{array}{l}\text { Originada em } \\
\text { morcegos }\end{array}$ & $\begin{array}{l}\text { Principal intermediário animal } \\
\text { responsável por infeção humana }\end{array}$ \\
\hline $\begin{array}{l}\text { Hendra (henipavirus } \\
\text { equino) }\end{array}$ & 1994 & Austrália & confirmada & cavalos \\
\hline Nipah (paramyxovirus) & 1998-99 & $\begin{array}{l}\text { Malásia }+4 \\
\text { países }\end{array}$ & confirmada & porcos \\
\hline $\begin{array}{l}\text { SARS (síndrome } \\
\text { respiratória aguda } \\
\text { grave; coronavírus) }\end{array}$ & $2002-03$ & $\begin{array}{l}\text { China }+25 \\
\text { países }\end{array}$ & confirmada & civeta \\
\hline $\begin{array}{l}\text { MERS (síndrome } \\
\text { respiratória do Oriente } \\
\text { Médio; corona vírus) }\end{array}$ & 2012 & $\begin{array}{c}\text { Arábia } \\
\text { Saudita }+26 \\
\text { países }\end{array}$ & suspeita & camelo \\
\hline EBOLA (ebolavirus) & $\begin{array}{c}1976 \\
1995,2000 \\
2002,2007 \\
2014-16,2018- \\
19\end{array}$ & $\begin{array}{l}\text { (Zaire) } \\
\text { Républica do } \\
\text { Congo }+6 \\
\text { países }\end{array}$ & $\begin{array}{l}\text { Altamente } \\
\text { suspeita }\end{array}$ & $\begin{array}{c}\text { Acreditasse que o surto de Ébola } \\
(2014) \text { iniciou-se } \\
\text { com transmissão morcego- } \\
\text { humano, primatas não humanos } \\
\text { foram indicados em anteriores } \\
\text { surtos }\end{array}$ \\
\hline $\begin{array}{c}\text { COVID } 19 \text { (corona } \\
\text { vírus) }\end{array}$ & 2019 & $\begin{array}{l}\text { China }+227 \\
\text { países }\end{array}$ & suspeita & ainda indeterminado \\
\hline
\end{tabular}

Fonte: adaptado de Wang et al. (fev, 2020:33)

Uma revisão efetuada por Zinszer (2017) elenca como preditores da EVD aspetos sociodemográficos e aspetos ambientais tais como: (i) crescente ocupação humana de nichos ecológicos para desflorestação e exploração de atividades económicas várias, (ii) aumento da densidade populacional; (iii) pobreza, (iv) educação; (v) fatores comunicacionais: descodificação da mensagem e acesso a meios de difusão; densidade rodoviária; (vi) fatores culturais; (vii) fatores físico-climáticos específicos (variação da temperatura, humidade característica da África equatorial).

Piot, Soka \& Spencer (2019), também num registo retrospetivo, fazem o balanço sobre lições aprendidas com o surto EVD 2018-19, sublinhando que os mais recentes surtos de doenças infeciosas prejudicaram a saúde global numa escala sem precedentes, associando pesados custos para a saúde humana, funcionando algumas vezes como gatilho para despoletar crises económicas e de segurança que urge prevenir: «Hoje, uma confluência de fatores socioeconómicos, políticos e fatores ambientais está a acelerar a taxa de emergência de doenças infeciosas. Com o aprofundamento da globalização, esses patógenos são cada vez mais móveis e as ameaças que representam são de natureza global.» (Piot, Soka \& Spencer, 2019:334).

As reflexões de Bhatnagar et al., 2016; Quaglio et al., 2016 e Piot, Soka \& Spencer, 2019, convergem nas fragilidades identificadas nos mais recentes surtos de EVD, quer ao nível das determinantes sociais em saúde características dos países mais pobres, quer ao nível das estratégias de prevenção tardiamente acionados ou procrastinadas pela comunidade internacional. Relapsamente, parecem não compreender que a globalização das trocas e das viagens é também a globalização dos agentes patogénicos que, com crescente frequência e virulência, atingem de um modo cada vez mais célere e impactante novas geografias. O raio de alcance foi fortemente ampliado pelo crescente número de voos intercontinentais sem escala, progressivamente mais acessíveis, tal como o foi o transporte a vapor no século XIX.

A pobreza extrema e alguns hábitos culturais, colocam parte significativa da população, mesmo em áreas urbanas, num cenário de vulnerabilidade, quer pela fragilidade da habitação e do saneamento, quer pela escassez de acesso a proteínas, o que impulsiona o consumo de carne de animais selvagens (bush meat), incluindo na dieta perigosos reservatórios virais, como morcegos e alguns primatas. Nas cidades e nas áreas remotas, hábitos culturais e religiosos que conformam rituais fúnebres, implicam o manuseamento de cadáveres de familiares falecidos, com lavagem, toque e beijo dos corpos, resultando num importante fator de contágio (Bhatnagar et al., 2016; Piot, Soka \& Spencer, 2019).

A crescente pressão pelo aumento da produção alimentar e pela exploração de recursos florestais, nomeadamente madeiras exóticas, e intensificação da produção animal, tem levado as comunidades 
humanas a invadirem nichos ecológicos sensíveis, obrigando à migração de espécies que funcionam como reservatórios de vírus, como tem acontecido na África Central com o morcego das frutas, arrastando o potencial de infeção para territórios naïve, potenciando o contágio de outras comunidades. À mobilidade de espécies animais, associa-se a intensa mobilidade humana, impulsionada por razões históricas e étnicas anteriores ao traçado das fronteiras colonias onde, relações tribais, afinidades familiares, a necessidade de comércio em mercados de rua, a par de extensas e porosas fronteiras, colocam em contacto comunidades que se movem diariamente entre países, privilegiando as principais rotas de transporte rodoviário de mercadorias que, nestes cenários, constituem uma oportunidade e uma ameaça à sobrevivência.

A fragilidade dos sistemas locais de saúde é causa e consequência da insuficiência de recursos públicos nacionais, das carências de educação e de formação de técnicos qualificados, do perfil epidemiológico em transição, ainda afligido pelo impacto presente do VIH/AIDS, pelas crises humanitárias excessivamente prolongadas no tempo, associadas a fatores climáticos, confrontos militares e práticas cleptocráticas. Em comum, os 3 artigos de reflexão sobre surtos de EDV, apontam a fragilidade dos sistemas de vigilância sentinela instalados no terreno, quer de laboratórios, quer de técnicos de saúde, que sofrem de um crónico subfinanciamento e dependência de doações internacionais. Num contexto de risco sanitário global, é importante que os sistemas de saúde pública, in loco, disponham de valências essências e independentes para deteção, informação e monitorização atempada de quaisquer ameaças:

\begin{abstract}
«Os países devem fortalecer suas principais capacidades para prevenir, detetar e responder a surtos, com proporcionalidade investimentos nacionais e, quando necessário, internacionais. Sistemas de saúde fortalecidos devem responder às pessoas, direitos e necessidades, abordando os problemas de saúde quotidianos que experiência e ameaças emergentes. Uma força de trabalho em saúde forte e apoiada é central para um sistema de saúde robusto. No início do surto de Ébola na África Ocidental, muitos funcionários da linha de frente não tinham treinamento apropriado para a cenários de emergências. Vários profissionais de saúde operavam em ambientes inseguros, com equipamento inadequado, mal remunerados, o que afetou a sua prontidão, segurança, motivação e qualidade de cuidados que eles poderiam prestar. (Piot, Soka \& Spencer, 2019:334).
\end{abstract}

Bhatnagar et al. (2016:148), corrobora esta declaração, sublinhando que, em muitos dos países onde frequentemente eclodem surtos infeciosos, falta material de proteção individual, com stocks cronicamente insuficientes, agravados por alguma impreparação de atuação no terreno por parte de Organizações Internacionais (OI) de referência como a OMS, que reiteradas vezes responde de forma pouco assertiva e tardia:

«Sucedeu um intervalo de 3 meses entre o primeiro caso relatado [EDV] e a confirmação da doença. Em mais 5 meses 1.000 mortes ocorreram antes da OMS declarar as ocorrências como uma emergência de saúde pública. O atraso nas medidas de resposta deram ao vírus uma margem de manobra para se espalhar».

Quaglio et al. (2016), ao analisar a atuação da União Europeia como ator internacional com responsabilidades políticas e sanitárias na contenção de ameaças globais, sublinha o mesmo nível de indecisão e de atraso na mobilização de recursos materiais e humanos altamente qualificados, observando-se uma dificuldade de articulação política e operacional entre os parceiros europeus.

Frequentes vezes, esta situação de relaxamento e de impasse de ação é percecionada pelas populações como um jogo de atores políticos onde, as autoridades locais, supostamente ampliam a incidência e os danos gerados pela epidemia de modo a obter dos doadores internacionais financiamentos e ajuda humanitária de maior dimensão:

\begin{abstract}
«A crença inicial das pessoas foi de que os governos inflacionam o número casos e mortes para obter ajuda internacional. Isso resultou em elevada resistência em adotar medidas preventivas de saúde pública. (...) A alta letalidade do surto alimentou um mal-entendido que, os doentes internados em centros de tratamento significa morte certa. Isso fez o isolamento com que o isolamento de pessoas infetadas fosse extremamente difícil de concretizar, favorecendo a disseminação da doença.» (Bhatnagar et al., 2016:148).
\end{abstract}

Para além da recusa de confinamento/internamento dos doentes infetados aumentar exponencialmente o risco de difusão deste tipo de epidemias de elevado contágio, a ocultação intencional de infetados pelos próprios e pelas comunidades, inviabiliza a realização de inquéritos epidemiológicos essenciais 
para se compreenderem as rotas de transmissão, identificar a sua génese, local ou importada, bem como o nível de disseminação na comunidade e as medidas de saúde pública correspondentes.

As mais recentes ameaças à saúde global, envolveram zoonoses que passaram a barreira de espécie, transformando-se numa Emergência de Saúde Pública Internacional (Public Health Emergency of International Concern - PHEIC). Neste contexto, Wang et al. (2020) reforçam a importância de se envolverem equipas multidisciplinares nas missões de apoio em saúde pública, tal como aconteceu em 2003 com a SARS-CoV onde, para além de peritos chineses, a OMS inclui na sua delegação 8 peritos internacionais, sete dos quais eram veterinários com larga experiência em saúde animal. Na presente ameaça gerada pelo 2019-nCoV, e ao contrário do que se exigia, a OMS não conseguiu impor ao seu parceiro chinês uma equipa adequadamente qualificada:

«Embora reconhecendo o tremendo esforço da equipe CDC-China na resposta precoce ao surto de 2019-nCoV, o pequena número de membros da equipe treinados em saúde animal foi provavelmente uma das razões do atraso na identificação de animal (s) intermediário (s), o que, provavelmente, pode ter contribuído para a propagação do vírus numa região de o mercados onde os animais selvagens eram negociados e onde, posteriormente encontrado foram encontrados fortes evidencias contaminação. Infelizmente a identificação de que animal estava envolvido na transmissão permanece desconhecida.» (Wang et al. 2020: e34).

\title{
PREPARAÇÃO E COOPERAÇÃO INTERNACIONAL EM CENÁRIOS DE EMERGÊNCIA SANITÁRIA: FRAGILIDADES ANUNCIADAS NUM CONTEXTO DE ECONOMIA GLOBAL
}

A observação e análise destes relatos e o contexto de atuação dos atores internacionais terá, obrigatoriamente, que ser observada e analisada no âmbito das obrigações internacionais que, em sede de OMS, exortam e comprometem os Estados, através do disposto no Regulamento Sanitário Internacional - $R S I$ ), criado em 1969, vinculando no presente 196 países signatários ao cumprimento de procedimentos e boas práticas de controlo sanitário internacional aplicado a bens, animais e pessoas viajantes. Desde a última revisão (RSI - 2005), introduziu-se o conceito de emergência de saúde pública (Public Health Emergency of International Concern - PHEIC), definindo-o como um evento extraordinário que constitui risco para a saúde pública de outros Estados e que exige uma resposta internacional coordenada. Assim, para além das responsabilidades nacionais, os Estados têm de se comprometer com o desenvolvimento e aperfeiçoamento de estratégias de preparação (preparedness). O conceito de preparação tem vindo a ser discutido de uma forma mais ampla desde 2005. Slepski et al. (2005) definem preparação como a prontidão de uma jurisdição política para reagir construtivamente às ameaças do ambiente de forma a minimizar as consequências negativas do impacto na saúde e segurança das pessoas e na integridade e funcionamento das estruturas e sistemas físicos. Mais recentemente a OMS, em sede do Comité de Acompanhamento de Preparação Global (Global Preparedness Monitoring Board, 2019) definiu o conceito de preparação como:

\begin{abstract}
«A capacidade (conhecimento, capacidade e sistemas de organização) dos governos, organizações profissionais, comunidades e indivíduos para antecipar, detetar e responder eficazmente, e recuperar do impacto de emergências, perigos, eventos ou condições de saúde prováveis, iminentes ou atuais. Significa colocar e criar mecanismos que permitam às autoridades nacionais, às organizações multilaterais e às organizações de socorro estar conscientes dos riscos e mobilizar rapidamente pessoal e recursos quando surge uma crise.»
\end{abstract}

Kandel et al. (2020), tirando partido dos dados de avaliação externa voluntária - State Party Annual Report (2018, apud Kendal, 2020), recolhidos para monitorizar os compromissos de ação previstos no $\mathrm{RSI}$, através de instrumentos de avaliação conjunta, revisão pós-ação e exercícios de simulação, cobrindo 6 domínios-chave: (i) Capacidade de prevenção, (ii) Capacidade de deteção; (iii) Capacidade de resposta; (iv) capacidade de ativação; (v) Capacidade de prontidão operacional, incluído nas regiões OMS; produziu um estudo que avalia as capacidades de segurança sanitária no atual contexto da COVID-19 através de um índice comporto de 18 indicadores. Na sua investigação concluiu que, apenas $76 \%(n=138)$ dos 182 países incluídos foram avaliados como tendo capacidade global de deteção de nível $4-5^{3}$, sendo que $33 \%$ dos países $(n=60)$, evidenciaram capacidade de prevenção e resposta de

\footnotetext{
${ }^{3}$ Nível 1: muito pouca capacidade funcional para prevenir e controlar o risco ou evento; Nível 2: Pouca capacidade funcional disponível em uma base ad-hoc com o apoio de recursos externos; Nível 3: O país é funcionalmente capaz no nível nacional; no entanto, a eficácia é baixa nos níveis subnacionais; Nível 4: O país é funcionalmente capaz de lidar com vários eventos nos níveis nacional e subnacional; Nível 5: A capacidade funcional do país está bem avançada e sustentável em todos os níveis dos sistemas de saúde (Kandel et al; 2020: 4).

DOI:http://dx.doi.org/10.14393/Hygeia0054631 Hygeia Edição Especial: Covid-19, Jun./2020 p.321 - 335, pág.326
} 
nível 1 - 2 (ver fig.1), a maioria dos quais classificados como países de baixo rendimento e médio-baixo rendimento pelo Banco Mundial.

Figura 1 - Posicionamento dos países no que respeita indicadores-chave de resposta a emergência sanitária

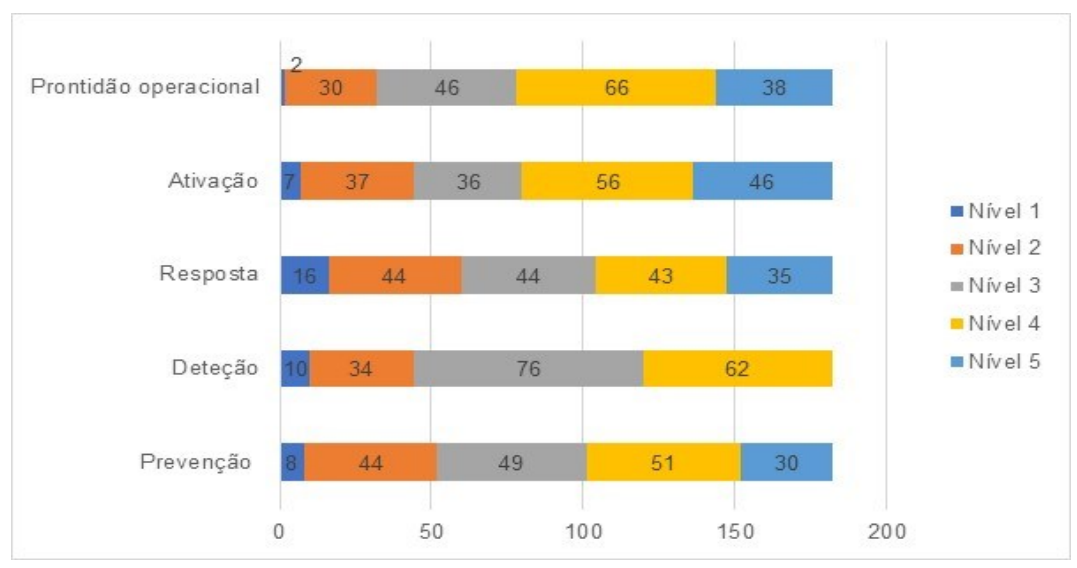

Fonte: Kandel et al. (2020: 4).

Neste contexto, Piot, Soka \& Spencer (2019:336) sublinham a necessidade de se adotarem estratégias transversais e urgentes, como condição sine qua non para a preparação de respostas eficazes, envolvendo comunidades locais, capacitadas e educadas para compreenderem as mensagens e reagirem a situações de stress:

\begin{abstract}
«Tecnologias médicas inovadoras, por si só, não são suficientes para prevenir e conter epidemias sem grandes esforços para obter a confiança das comunidades e entender a suas(s) perceções de medidas de controle adaptadas as suas necessidades. $O$ envolvimento da comunidade e das atividades de ciências sociais devem ser incluídos como componentes centrais da tomada de decisão, agenda de investigação e priorização de recursos durante a conceptualização, fases de planejamento e implementação de iniciativas de saúde pública.»
\end{abstract}

Para além do descrito, Kandel et al. (2020), observando o percurso de reação à emergência global gerada no contexto da COVID-19, enfatiza que a resposta a um surto depende não apenas da disponibilidade de recursos humanos e financiamento adequados, mas também da capacidade de gerir a logística de emergência (incluindo o manuseio de cadeias de suprimentos para produtos essenciais necessário durante uma emergência), nos quais se incluem dispositivos de proteção individual (DPI) adequados, quer para os técnicos de saúde quer para a população exposta ao risco de contágio. Neste ponto, a capacidade operacional, mesmo dos países mais ricos, revelou elevados níveis de fragilidade.

\title{
OBSERVAÇÃO DE INDICADORES EPIDEMIOLÓGICOS BÁSICOS E PRELIMINARES
}

Depois da primeira notificação das autoridades chinesas junto da OMS, anunciando a deteção de uma pneumonia de causa desconhecida localizada em Wuhan, China, a 31 de dezembro de 2019, a 3 de janeiro de 2020, já existiam 44 casos relatados, 11 pacientes estavam gravemente doentes, e os restantes mantinham condição estável (WHO - Disease Outbreak News; 5.1.2020), todos no interior da China. A 20-21 de janeiro, a delegação da OMS na China visita várias infraestruturas aeroportuárias e de saúde em Wuhan e discute o plano da China para a definição de caso SARS-CoV2. Isso permitiria que a China e a comunidade internacional obtivessem uma imagem mais clara sobre a gravidade e capacidade de difusão do novo coronavírus. A 30 de janeiro, a China confirma 7736 infetados, 170 mortos, ao que se somam mais 100 casos distribuídos por quatro continentes, envolvendo notificações de 19 países (Fig.2), levando a OMS a declarar o surto como Emergência de Saúde Pública Internacional. Nesta data, a OMS publica informação que permitia avaliar que, para além de diversos casos transmitidos por viajantes chineses e não chineses, pelo menos 3 casos notificados fora do território chinês, correspondiam a transmissões secundárias, envolvendo pessoas que não tinham feito qualquer viagem ao exterior. O protocolo de preparação foi seguido, recomendando-se um conjunto de medidas semelhantes às informadas em 2012 quando do surto MERS, já que estaríamos a enfrentar, pela terceira vez consecutiva uma ameaça global associada a uma infeção respiratória aguda. 
Figura 2 - Situação epidemiológica do SARS-CoV2 a 30 de janeiro 2020

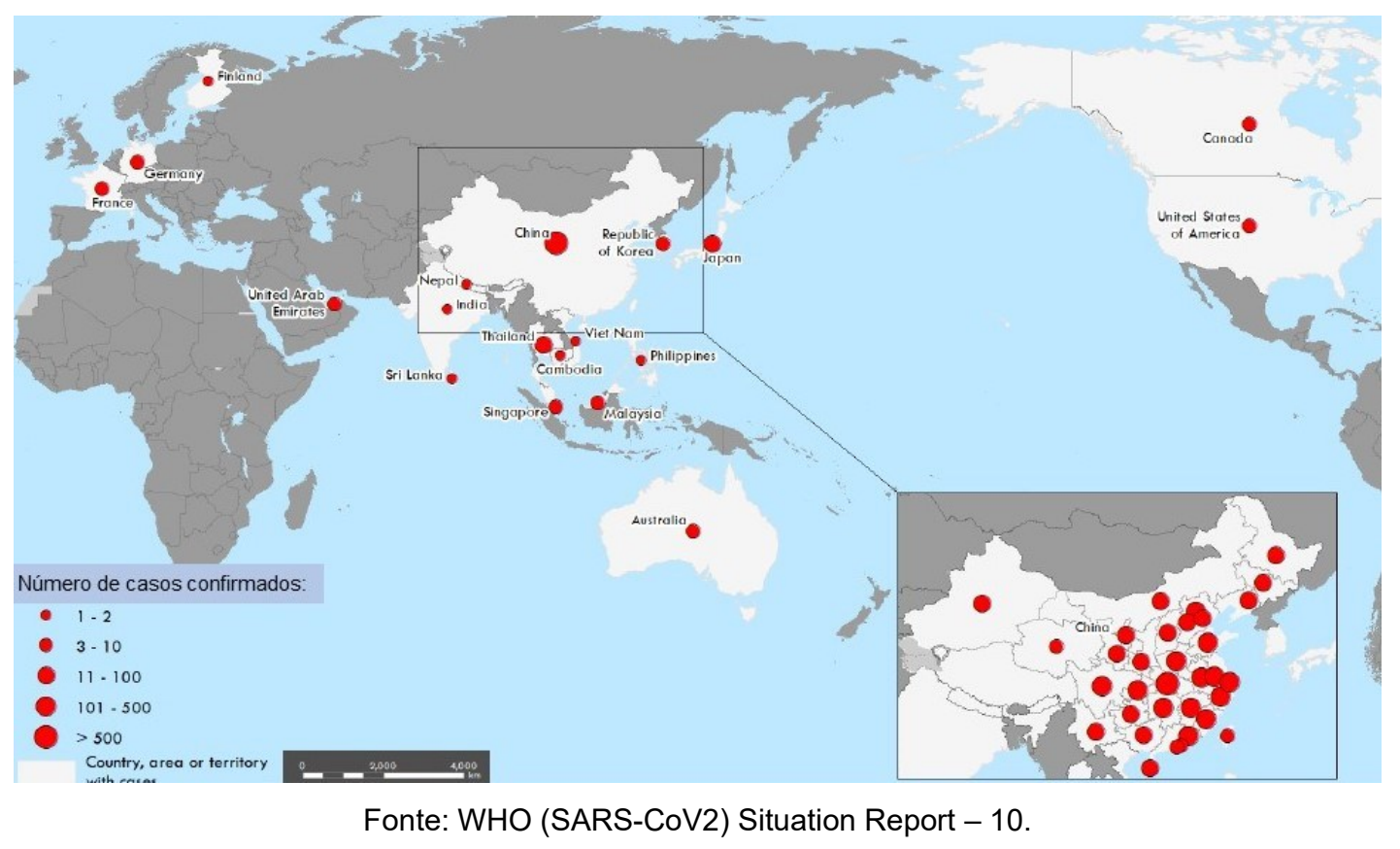

Se compararmos a difusão espaço-temporal da SARS e da SARS-CoV2 (Fig.3) percebemos que terão de existir fatores diferenciadores capazes de explicarem a diferença observada, quer na incidência nos primeiros 30 dias doença, quer na velocidade de propagação e alcance geográfico, atingindo 7736 notificações SARS-CoV2 em 31 dias, um intervalo de tempo 8 vezes inferior para uma incidência aproximada das notificações SARS.

Figura 3 - Linha de tempo para a incidência e difusão geográfica da SRAS e SARS-CoV2

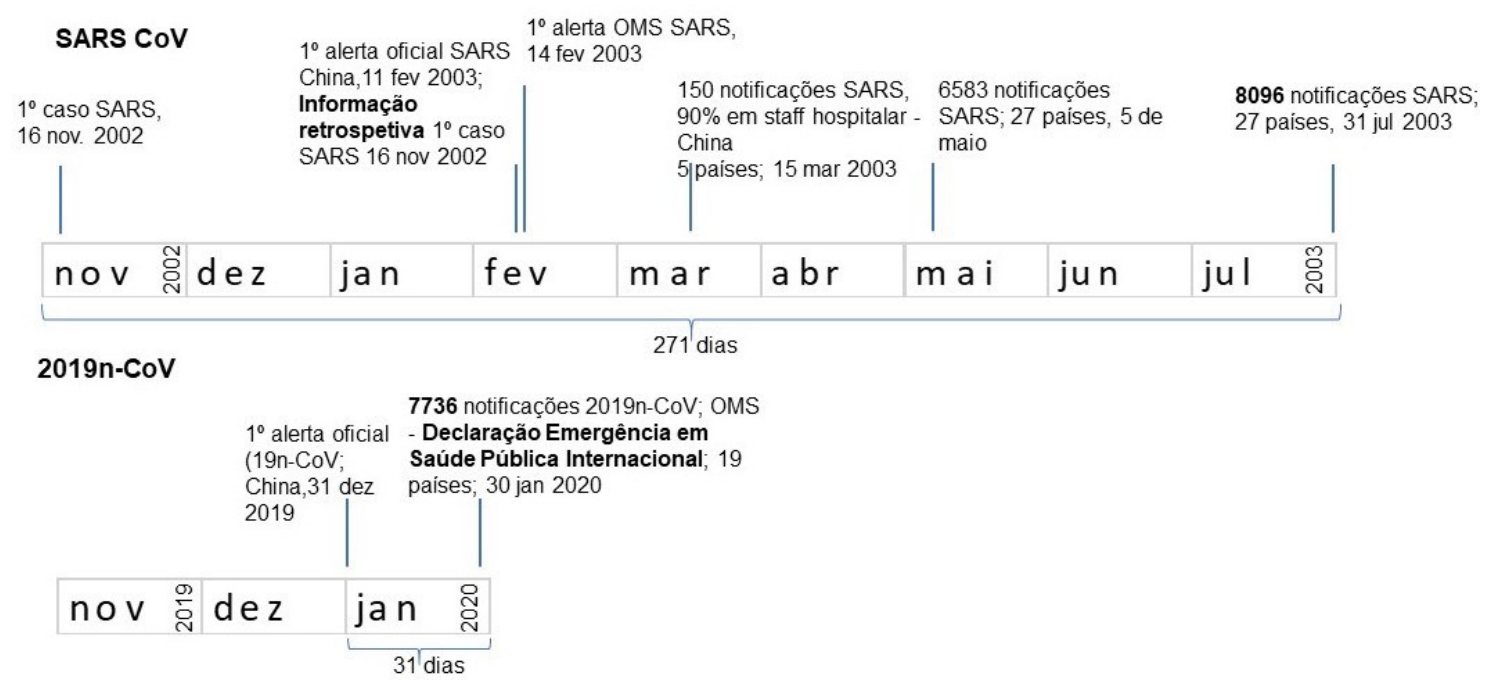

Fonte: dados WHO (2002,2003;2019;2020); Elaboração autor

Do ponto de vista da história natural da doença, estamos perante vírus da mesma família (coronavírus), mas com períodos de incubação ligeiramente diferentes. De acordo com um documento de consenso 
da OMS (2003b), para a SARS reportou-se um tempo médio de incubação de 5 dias, com intervalo de variação de $2-14$ dias. No caso do SARS-CoV2, dados preliminares publicados por Lauer et al. (2020), baseados 181 casos confirmados e notificados fora da China continental, evidenciaram um tempo médio de incubação de 5,1 dias [IC 4,4 - 7.0], e uma variação de 2,1 -14,7 dias, sendo estes resultados consistentes com outros estudos preliminares já publicados (Huang, Wang; Li, 2020).

Um outro fator que poderia explicar a diferença na velocidade de propagação da doença seria o número básico de reprodução $\mathrm{R}_{0}{ }^{4}$. Dados preliminares publicados por D'Arienzo; Coniglio, 2020, para o SARSCoV2, tendo como base o surto inicial observado em 9 cidades italianas (25 fev. - 12 mar; 2020), verificaram que o R0 variava entre $2,43-3,10$, em linha com os valores publicados por Zhao et al. (2020; apud D'Arienzo; Coniglio, 2020:3) que apresentaram valores para $R_{0}$ de 2,24 - 3,58.

Os valores de $R_{0}$ estimados preliminarmente para o SARS-CoV2 não se afastam expressivamente dos valores que a OMS apresenta para $R_{0}=3$ para a SARS, tal como é apresentado num documento de consenso publicado em 2003 (OMS, 2003b:12). Perante os dados epidemiológicos até aqui apresentados parece, pois, pertinente examinar o contexto potenciador de difusão de uma doença infeciosa.

\section{LEITURA GEOGRÁFICA DE UMA PANDEMIA NUM CONTEXTO DE GLOBALIZAÇÃO}

No âmbito da Geografia da Saúde e no contexto das patologias infeciosas, o conceito de difusão ocupa um lugar central desde a década de 50, evocando dois conceitos distintos: difusão por expansão e difusão por relocalização (Cliff, 1981; Haggett, 2000; Nossa, 2012). No primeiro caso, difusão por expansão, com particular aplicação na investigação da difusão de patologias infeciosas, o evento a ser difundido permanece na região de origem, podendo mesmo verificar-se a sua intensificação à medida que novas áreas vão sendo atingidas em períodos subsequentes (t1, t2...tn). Neste caso, o processo pode ocorrer por duas maneiras:

- Difusão por contágio, dependendo do contacto direto, sendo um processo fortemente influenciado pela distância, comportando-se o fenómeno de modo centrífugo;

- Difusão hierarquizada, descreve a transmissão através de uma sequência ordenada de classes ou lugares, como por exemplo de uma área metropolitana para áreas mais periféricas.

A observação de series temporais para a eclosão de surtos de sarampo (1945 - 1970) feita por Bartlett (apud Haggett, 2000), permitiu determinar um limiar crítico de endemicidade os $250.000-300.000$ habitantes para os EUA, verificando-se uma coincidência quantitativa deste indicador para as investigações produzidas com populações inglesas (Haggett, 2000). Por esta via, admite-se para o sarampo, bem como para outras patologias, com reservatórios exclusivamente humanos que, se o tamanho de uma população numa determinada área for inferior ao limiar crítico traçado, a doença considerar-se-á extinta, pelo que a ocorrência de novos surtos deriva de reintroduções (relocalizações) a partir de reservatórios externos à área.

Mais tarde, Gould (1993), ao investigar a difusão do HIVIAIDS e observando a progressão hierárquica da doença nos EUA, aplica o "modelo de gravidade" na investigação da provável atração que centros urbanos hierarquicamente superiores exercem sobre outros em termos de potenciais contactos, uma vez que a interação entre indivíduos ocorrerá, com maior probabilidade, com centros de nível superior, numa razão proporcional ao tamanho das cidades (Nossa, 2012). Tendo em conta a densidade populacional e os meios de transporte disponíveis (que podem incluir voos diretos, comboios rápidos, autoestradas), Gould calculou o potencial de interação urbana, medindo a probabilidade do processo de infeção por HIV se deslocar hierarquicamente entre áreas com elevado potencial de interação, originando epicentros regionais de contágio que, em termos espaciais, podem não tocar áreas rurais de menor dimensão, quer pela menor densidade populacional quer pela menor conetividade.

Apesar de estarmos perante vírus diferentes, com elevada probabilidade de envolverem reservatórios animais com elevada importância na eclosão da doença SARS-CoV2, e de termos meios de contágio diferenciados entre o HIV e o SARS-CoV2, o papel da conectividade entre territórios parece ser, no atual contexto da pandemia, um fator significativo.

\footnotetext{
$4 \mathrm{R}_{0}$ : número básico de reprodução $\mathrm{R}_{0}$, é o número médio de infeções causadas por um indivíduo infetado durante todo o período infecioso no início de um surto (D’Arienzo; Coniglio, 2020).
} 
O contexto epidemiológico que hoje vivemos, dominado por patologias doenças crónico-degenerativas, mas interrompido por surtos epidémicos crescentes, com impacte universal, causado por vírus ou bactérias, também deve ser lido no contexto da liberalização das trocas de bens e serviços, associados a uma mobilidade global intercontinental sem precedentes na história humana. Neste contexto, ainda numa fase anterior à emergência da China como membro de pleno direito da Organização Mundial do Comércio, o que correu em 2001, Fidler (1996) sublinhava a necessidade urgente de se adequar o RSI à nova realidade que emergia com a globalização e desregulação dos mercados, antevendo um incremento significativo do transporte aéreo de pessoas e bens, bem como a fragmentação das cadeias de produção:

«A globalização foi definida como o "processo de desnacionalização dos mercados, leis e políticas no sentido de entrelaçar povos e indivíduos em prol do bem comum". A globalização distingue-se da internacionalização, que é definida como "um meio de permitir que os estados-nações satisfaçam o interesse nacional em áreas onde são incapazes de fazê-lo de per se. A internacionalização envolve cooperação entre estados soberanos, enquanto a globalização refere-se a um processo que está minando ou corroendo a soberania. (...) A globalização surge da confluência de algo velho e algo novo nas relações internacionais. Envolve o processo muito antigo de relações políticas e económicas entre estados soberanos. O novo elemento é a intensificação e expansão de tais relações possibilitadas pelos avanços tecnológicos em viagens, comunicações e computadores.» (Fidler, 1996:77).

No caso específico da China, à semelhança do que ocorreu com outras nações, a adesão à Organização Mundial do Comércio $(\mathrm{OMC})$ e a desregulação progressiva do setor dos transportes à escala global, não só permitiu que o mercado de aviação internacional expandisse as suas rotas para novos territórios, como também consolidou redes de partilha no mercado internacional existente. $\mathrm{Na}$ China, o número de passageiros utilizadores de transporte aéreo internacional entre 1990 e 2000 aumentou de 1,09 milhões para 6,24 milhões, o que corresponde a uma taxa de crescimento anual de $19,1 \%$, muito mais rápida do que a taxa de crescimento global $(5,5 \%)$. Adicionalmente, a participação do mercado da aviação internacional na China aumentou de 1,7\% para 6,0\% (Wang, Yang, Wang; 2019). Entre 2000 e 2016, o número de aeroportos internacionais em cidades chinesas passou de 22 para 77 , enquanto as ligações internacionais de cidades estrangeiras com a China passou de 56 para 146 (Fig.4).

Figura 4- Evolução das ligações aéreas internacionais da China com outros países (2000-2016)

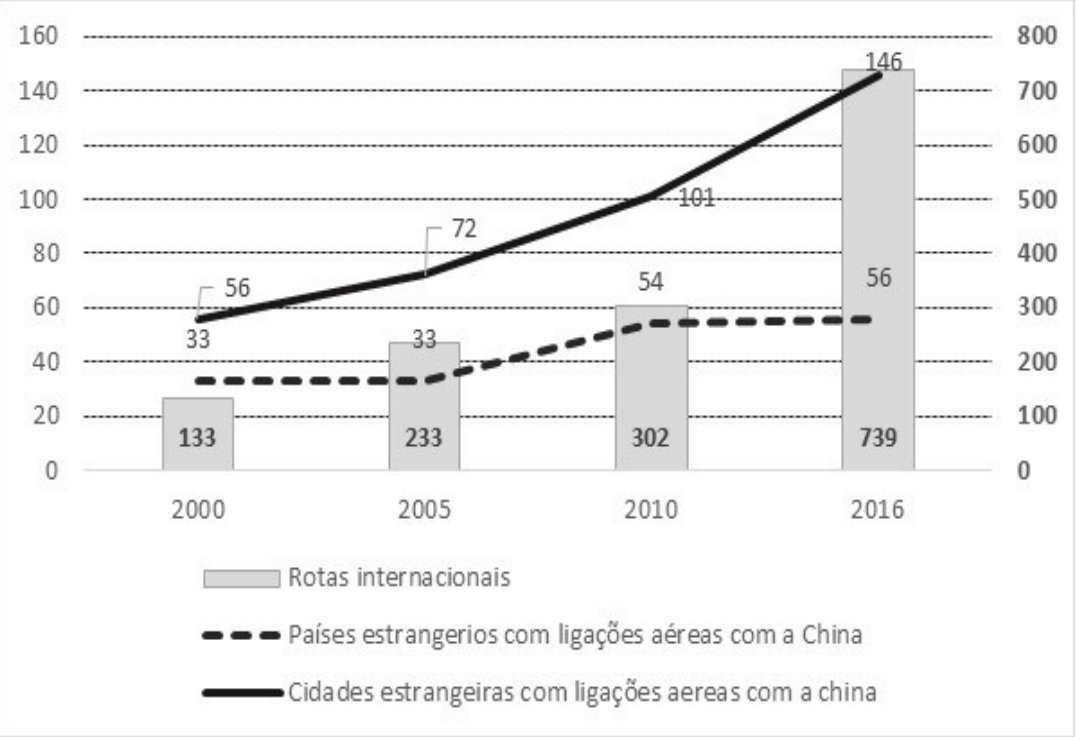

Fonte: dados Wang, Yang, Wang (2019); Elaboração autor.

O projeto global do governo central da China - "Rota da Seda", permitiu alavancar avultados investimentos para a dinamização de uma extensa rede de infraestruturas logísticas que chegam até à Europa, por via aérea, marítima e ferroviária. Em consequência deste plano de diplomacia económica, 
a Associação Internacional de Transporte Aéreo (IATA, 2017; apud Wang, Yang, Wang; 2019) alterou as suas expectativas sobre o centro de gravidade das viagens aéreas mundiais para oriente, mais afastado do eixo EUA-Europa, tendo a China atingido o valor de 611 milhões de passageiros em 2018, muito próximo dos 637 milhões que os 27 países da UE transportaram no mesmo período e dos 889 milhões de passageiros transportados pelos EUA (Fig.5).

Figura 5 - Evolução do transporte aéreo de passageiros (1970-2018)

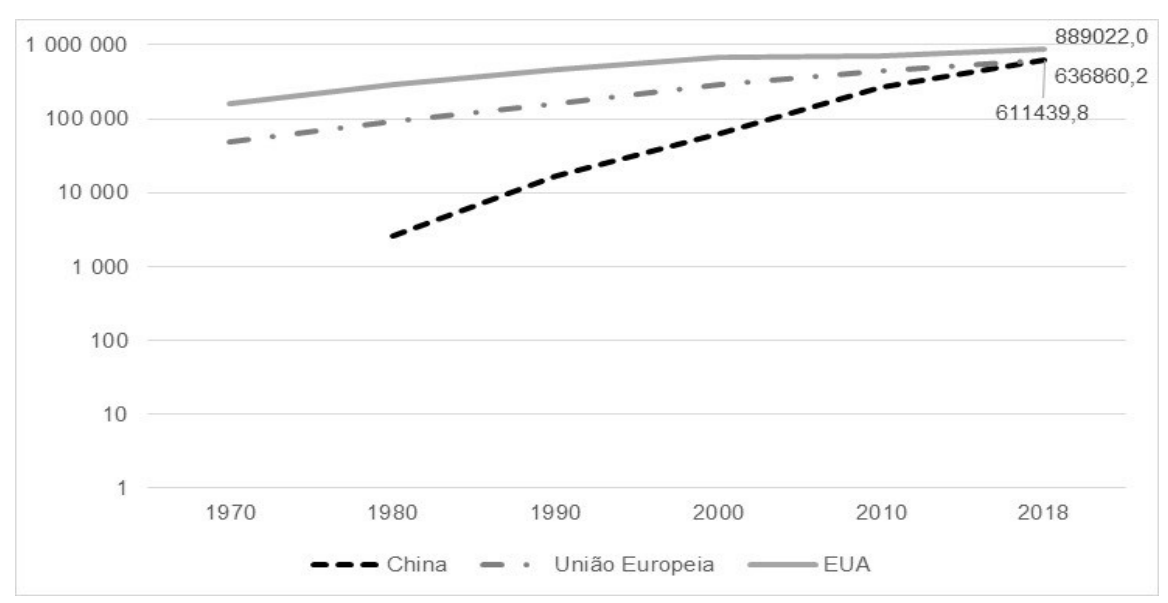

Fonte: dados World Bank, 2020; Elaboração autor.

Assim, o tráfego aéreo global de passageiros em 2018 foi de 4,282 mil milhões, o que equivale a 2,5 vezes mais passageiros transportados do que no início do século XXI, com aproximadamente 1,7 mil milhões de passageiros (2000).

Todavia, os efeitos da globalização e o seu impacte na difusão de epidemias não são só mensuráveis ao nível da deslocação de pessoas e bens. A negociação e reconfiguração de barreiras alfandegárias como incentivo ao livre comércio, a par da desregulação do setor dos transportes, com consequente redução do custo do transporte de carga, permitiu a redefinição do comércio/serviços mundiais em termos de produção e de vantagens comparativas, instalando-se a segmentação regional/global da cadeia produtiva (outsourcing / offshoring). A revolução das TIC associada à digitalização da produção industrial (Indústria 4.0), permitiu uma significativa redução dos custos de coordenação de atividades produtivas realizadas à distância, mesmo que com elevado nível de complexidade. Atividades de menor valor acrescentado e/ou mão de obra intensivas foram transferidas para geografias onde o custo salarial é significativamente menor, a legislação laboral e ambiental é extremamente flexível e a proteção social é nula ou inexistente.

Neste contexto, muitos países asiáticos, liderados pela China, desde 2000, assumiram-se como mega fornecedores mundiais de produtos transformados, incluindo bens e equipamentos que, em situação sanitária de emergência, são vitais para assegurar a primeira intervenção.

No caso dos produtos de proteção individual (DPI) para uso hospitalar, apenas 3 países, China, a Alemanha e os EUA são responsáveis por $40 \%$ da produção e comércio mundial (Fig.6).

No cenário de pandemia de SARS-CoV2 e por ser, uma vez mais, uma doença infeciosa respiratória aguda, a atenção de todos os países recaiu sobre o stock e compra de produtos médicos, especificamente produtos para prevenção, teste e tratamento, gerando uma inflação de preços e uma escassez sem precedentes de produtos de proteção e suporte de vida para uso hospitalar e proteção da população exposta em cada país. 
Figura 6 - Principais países exportadores de produtos de proteção individual (2019)

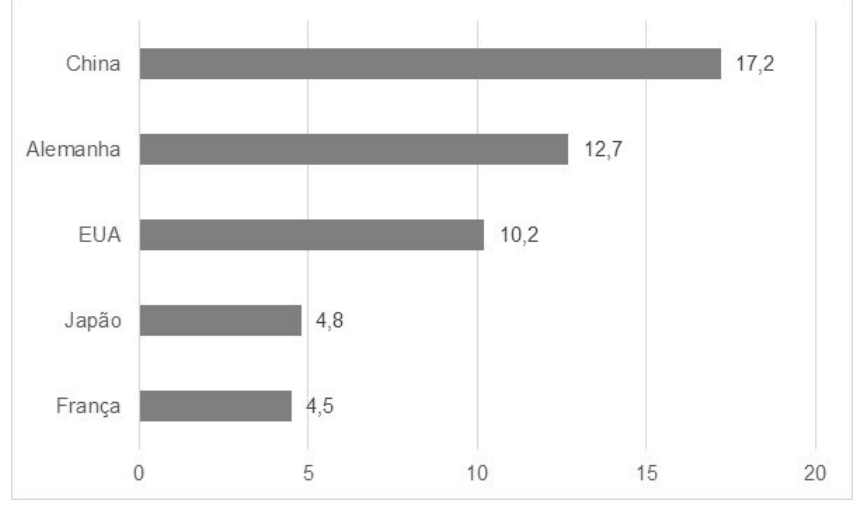

Fonte: dados WTO, 2020; elaboração autor

Nos últimos três anos (2017-2019), os EUA foram o maior importador de produtos médicos, representando $19 \%$ do total das importações mundiais em 2019. Como evidencia a Tabela 2, a Alemanha teve uma participação de $9 \%$, seguida pela China e pela Bélgica (6\%). Os outros importadores incluem os Países Baixos, Japão, Reino Unido, França, Itália e Suíça. Em termos da importação relativa de produtos médicos, face às importações totais de cada país, a compra ao exterior de produtos médicos pela Bélgica e pela Suíça representam cerca de $13 \%$ do total das suas importações. Entre os 10 principais importadores, a menor parcela é a da China, com apenas $3 \%$ das importações totais (WTO, 2020).

Tabela 2 - Principais países importadores de produtos médicos (2019)

\begin{tabular}{|c|c|c|c|c|c|c|}
\hline & $\begin{array}{c}\text { Valor (US\$ } \\
\text { biliões) }\end{array}$ & $\begin{array}{c}\% \text { importação de } \\
\text { todos os produtos }\end{array}$ & $\begin{array}{c}\text { Equipamento } \\
\text { médico }\end{array}$ & $\begin{array}{c}\text { Suprimentos } \\
\text { médicos }\end{array}$ & Medicamentos & $\begin{array}{c}\text { Produtos de } \\
\text { proteção }\end{array}$ \\
\hline EUA & 193,1 & 8 & 16 & 16 & 59 & 10 \\
\hline Alemanha & 86,7 & 7 & 12 & 18 & 57 & 13 \\
\hline China & 65 & 3 & 23 & 15 & 46 & 16 \\
\hline Belgica & 56,6 & 13 & 8 & 12 & 75 & 5 \\
\hline Países Baixos & 52,7 & 8 & 16 & 20 & 55 & 8 \\
\hline Japão & 44,8 & 6 & 16 & 16 & 56 & 13 \\
\hline Reino Unido & 41,1 & 6 & 11 & 15 & 62 & 12 \\
\hline França & 40,5 & 6 & 12 & 20 & 53 & 15 \\
\hline Itália & 37,1 & 8 & 9 & 15 & 66 & 9 \\
\hline Suiça & 36,9 & 13 & 6 & 9 & 80 & 5 \\
\hline
\end{tabular}

Fonte: dados WTO, 2020; elaboração autor

Como foi amplamente discutido nas primeiras fases da pandemia SARS-CoV2, até se atingir a fase de incidência máxima da epidemia, a grande maioria dos países de elevado rendimento não tinha stocks suficientes de material de proteção individual para enfrentarem uma interrupção parcial ou total das cadeias de abastecimento, incluindo materiais para suporte avançado de vida, como máquinas de ventilação invasiva, colocando-se numa posição de gigantes com pés de barro, obrigando a compras de emergência e à ativação de legislação excecional aplicada só em situações de catástrofe sanitária, de modo a obrigar a indústria nacional a reconverter a sua produção.

\section{CONCLUSÕES}

Como foi demonstrado, os níveis de desigual desenvolvimento entre regiões e grupos de países, o crescimento urbano acelerado, a crescente ocupação de nichos ecológicos sensíveis por comunidades 
humanas, obrigando à migração de espécies que funcionam como reservatórios de vírus, a ausência de um investimento adequado e duradouro na educação e qualificação de recursos humanos, o aumento do comércio mundial de matérias primas e de produtos transformados, conjuntamente, congregam um cenário de alerta quase continuo à medida que episódios pandémicos emergem.

A última revisão do RSI (2005), no seu prefácio, alertou para o crescente risco sanitário que o aumento das viagens e comércio internacional congregam no presente, potenciando riscos de saúde pública à escala internacional.

As lições deixadas pelas sucessivas epidemias de ébola, a última das quais atingiu a Europa e os EUA, bem como a eclosão da SARS (2002) e MERS (2012), demonstraram que o mundo precisa de estabelecer proactivamente sistemas operacionais de deteção e controlo de possíveis surtos de doenças, a par de níveis de preparação elevados, observados como um bem público global, e que devem envolver significativamente as comunidades locais, nacionais e internacionais (GPMB, 2019). A natureza da ameaça, as fragilidades e suscetibilidades da diplomacia, a hiperconectividade mundial, a par do risco de extensas perdas financeiras que, só no setor da aviação estão estimadas entre os 63 biliões de US\$ num cenário limitado, e os 113 biliões de US\$ num cenário extenso (IATA Economics, 2020), ao qual se junta a contração da riqueza global estimada em $0,9 \%$ (UN, 2020), e o elevado tributo de vidas humanas com mais de 4,2 milhões de infetados e 283 mil mortes (WHO, 10 maio 2020), deve fazer-nos refletir sobre o nível de preparação e de compromisso que os Estados e as OI devem priorizar. Andrews (2020) chama a nossa atenção de que, nos pós-pandemia, o comércio mundial poderá sofrer importantes alterações, com os lideres políticos como Trump e Emmanuel Macron, por motivos diferentes, a admitirem uma revisão significativa do liberalismo planetário, desta feita não para estancar emigrantes, mas como pretexto de elevarem o nível de segurança sanitária das sua populações: «O coronavírus é um terrível agente da "desglobalização". Interrompeu os movimentos das populações locais e dos turistas, impediu trabalhadores de se deslocarem para os locais de trabalho, fechou lojas e restaurantes cortou a cadeia logística de países.» (Andrews, 2020:28).

Do ponto de vista de prontidão internacional, esta emergência sanitária, demonstrou que, mesmo os Estados mais poderosos do mundo, em termos bélicos e lou comerciais, demonstraram elevadas fragilidades ao não terem garantido, desde o alerta inicial a 31 de dezembro, um stock adequado de materiais de proteção individual para o seu staff hospitalar e para as populações expostas, alargando cadeias de contágio, comportando-se como gigantes com pés de barro.

No presente, devemos ter a prudência e a humildade necessária para admitir que, as maiores consequências desta crise sanitária, ao nível do jogo de atores internacionais, ainda estão por compreender. A hiperglobalização mostrou da pior maneira a sua fragilidade: «Um vírus não tem a capacidade para inverter, de um dia para o outro a globalização. No entanto, talvez a Covid-19 tenha acelerado uma mudança já iniciada nas estruturas económicas que vigoram nos últimos 20 anos.» (Andrews, 2020:29).

\section{BIBLIOGRAFIA}

Andrews, K. Globalização: marcha-atrás a todo o vapor? In Courrier Internacional; n 291; maio 2020; (28-29).

Bhatnagar N, Grover M, Kotwal A, Chauhan H. Study of recent Ebola virus outbreak and lessons learned: A scoping study. Annals of Tropical Medicine \& Public Health. 2016;9(3):145-151. doi:10.4103/1755-6783.181658. https://doi.org/10.4103/1755-6783.181658

Cliff, A; Haggett, P. Atlas of Disease Distributions: analytic approaches to epidemiological data. Oxford: Blackwell Publishers; 1988.

D'Arienzo M, Coniglio A. Assessment of the SARS-CoV-2 basic reproduction number, R0, based on the early phase of COVID-19 outbreak in Italy [published online ahead of print, 2020 Apr 2]. 2020;. doi:10.1016/j.bsheal.2020.03.004. Acesso, 8 de maio de 2020. https://doi.org/10.1016/j.bsheal.2020.03.004

Farmer P. Social inequalities and emerging infectious diseases. Emerg Infect Dis. 1996;2(4):259-269. doi:10.3201/eid0204.960402. https://www.ncbi.nlm.nih.gov/pmc/articles/PMC2639930/ Acesso, 2 de fevereiro de 2020. https://doi.org/10.3201/eid0204.960402

Fidler DP. Globalization, international law, and emerging infectious diseases. Emerg Infect Dis. 1996;2(2):77-84. doi:10.3201/eid0202.960201. 
https://www.ncbi.nlm.nih.gov/pmc/articles/PMC2639823/. Acesso, 5 de fevereiro 2020. https://doi.org/10.3201/eid0202.960201

Gould, P. The Slow Plague, a geography of AIDS pandemic. Blackwell; 1993.

GPMB - Global Preparedness Monitoring Board Secretariat/WHO. Annual report on global preparedness for health emergencies. Geneva. https://apps.who.int/gpmb/assets/annual report/GPMB annualreport 2019.pdf Acesso, 31 de janeiro de 2020.

Grmek, M. História da SIDA. Ed. Relógio D’Agua. Lisboa; 1993.

Haggett, P. The Geographical Structure of Epidemics. Oxford: Clarendon Press; 2000.

Huang C, Wang Y, Li X, et al. Clinical features of patients infected with 2019 novel coronavirus in Wuhan, China. Lancet. 2020;395:497- 506. [PMID: 31986264] doi:10.1016/S0140-6736(20)30183-5; https://www.ncbi.nlm.nih.gov/pubmed/31986264 Acesso, 3 de maio de 2020. https://doi.org/10.1016/S0140-6736(20)30183-5

IATA Economics. COVID-19 Update impact assessment of the novel coronavirus. $5^{\text {th }}$ march, 2020. https://www.iata.org/en/iata-repository/publications/economic-reports/coronavirus-updated-impactassessment/ Acesso, 15 de março 2020.

Kandel, N; Chungong, S; Omaar, A; Xing, J. Health security capacities in the context of COVID-19 outbreak: an analysis of International Health Regulations annual report data from 182 countries. The $\begin{array}{lllll}\text { lancet.com } & \mathrm{Vol} & 395 & \text { March } & 2820.1047-1053 ;\end{array}$ https://www.thelancet.com/pdfs/journals/lancet/PIIS0140-6736(20)30553-5.pdf Acesso, 3 de maio de 2020. https://doi.org/10.1016/S0140-6736(20)30553-5

Lauer SA, Grantz KH, Bi Q, et al. The Incubation Period of Coronavirus Disease 2019 (COVID-19) From Publicly Reported Confirmed Cases: Estimation and Application. Ann Intern Med. 2020;172:577-582. [Epub ahead of print 10 March 2020]. Acesso, 8 de maio de 2020. https://doi.org/10.7326/M20-0504

Meade, M. Medical Geography. The Guilford press; 2nd Ed; NY; 2000.

Nossa, P. Geografia da Saúde: o caso da SIDA. Celta Editora; Lisboa; 2001.

Nossa, P. Saúde e Espaço: abordagem teórico-metodológica em Geografia da Saúde. Col. Biblioteca de Ciências Sociais. Ed. Afrontamento; Lisboa; 2012.

Pamuk, O. O que os Grandes Romances Pandémicos nos Ensinam. In E Revista do Expresso. Ed. 2480; 9 maio 2020: 22,23.

Piot, P; Soka, Mj; Spencer, J. Emergent threats: lessons learnt from Ebola. Int Health. 2019 Sep 2;11(5):334-337. doi: 10.1093/inthealth/ihz062. https://www.ncbi.nlm.nih.gov/pubmed/31385587 Acesso, 15 de março 2020. https://doi.org/10.1093/inthealth/ihz062

Quaglio G, Goerens C, Putoto G, et al. Ebola: lessons learned and future challenges for Europe. The Lancet Infectious diseases. 2016;16(2):259-263. https://doi.org/10.1016/S1473-3099(15)00361-8

Reglamento Sanitario Internacional (2005). https://www.who.int/ihr/publications/9789241580496/es/ Acesso, 3 de novembro de 2019.

Ujvari, S. C. A História da Humanidade Contada pelos Vírus. Editora Contexto. S.Paulo; 1996.

UN - World Economic Situation and Prospects: April 2020 Briefing, No. 136; https://www.un.org/development/desa/dpad/publication/world-economic-situation-and-prospects-april2020-briefing-no-136/ Acesso, 8 de maio de 2020.

Wang, Lin-Fa et al. From Hendra to Wuhan: what has been learned in responding to emerging zoonotic viruses. The Lancet; Volume 395, ISSUE 10224, e33-e34, February 22, 2020. https://doi.org/10.1016/S0140-6736(20)30350-0 
Wang; J; Yang, H; Wang, H. The Evolution of China's International Aviation Markets from a Policy Perspective on Air Passenger Flows. June 2019; Sustainability 11(13):3566. DOI: 10.3390/su11133566. https://www.researchgate.net/publication/334103828 The Evolution of China\%27s International Avi ation Markets from a Policy Perspective on Air Passenger Flows Acesso, 3 janeiro, 2019. https://doi.org/10.3390/su11133566

WHO - Consensus document on the epidemiology of severe acute respiratory syndrome (SARS). WHO/CDS/CSR/GAR/2003 (b). https://www.who.int/csr/sars/en/WHOconsensus.pdf Acesso, 3 de abril de 2020.

WHO. Disease Outbreak News; 2002; 2003; 2019; 2020. https://www.who.int/csr/don/en/

WHO. (SARS-CoV2) Situation Report - 10. https://www.who.int/emergencies/diseases/novelcoronavirus-2019/situation-reports

WHO. Severe Acute Respiratory Syndrome (SARS)-multi-country outbreak - Update 47; Studies of SARS virus survival, situation in China.5 may 2003. 5 May 2003. https://www.who.int/csr/don/2003 05 05/en/

World Bank - open data; https://data.worldbank.org/indicator. Accesso, 25 de fevereiro, 2020.

WTO - Trade in Medical Goods in the Context of Tackling COVID-19; inf. Note; 3 april; 2020 (1:16). https://www.wto.org/english/news e/news20 e/rese 03apr20 e.pdf Acesso, 3 de maio de 2020.

Zinszer K, Morrison K, Verma A, Brownstein JS. Spatial Determinants of Ebola Virus Disease Risk for the West African Epidemic. PLoS Curr. 2017;9: ecurrents.outbreaks.b494f2c6a396c72ec24cb4142765bb95. Published 2017 Mar 31. doi:10.1371/currents.outbreaks.b494f2c6a396c72ec24cb4142765bb95 Acesso, 3 de maio, 2020. https://doi.org/10.1371/currents.outbreaks.b494f2c6a396c72ec24cb4142765bb95 